\title{
Prostatic Arterial Embolization to Treat Benign Prostatic Hyperplasia
}

\author{
João M. Pisco, MD, PhD, Luis C. Pinheiro, MD, PhD, Tiago Bilhim, MD, \\ Marisa Duarte, MD, Jorge R. Mendes, MD, and Antonio G. Oliveira, MD, PhD
}

\begin{abstract}
PURPOSE: To evaluate whether prostatic arterial embolization (PAE) might be a feasible procedure to treat lower urinary tract symptoms associated with benign prostatic hyperplasia (BPH).

MATERIALS AND METHODS: Fifteen patients (age range, 62-82 years; mean age, 74.1 y) with symptomatic BPH after failure of medical treatment were selected for PAE with nonspherical $200-\mu \mathrm{m}$ polyvinyl alcohol particles. The procedure was performed by a single femoral approach. Technical success was considered when selective prostatic arterial catheterization and embolization was achieved on at least one pelvic side.
\end{abstract}

RESULTS: PAE was technically successful in 14 of the 15 patients $(93.3 \%)$. There was a mean follow-up of 7.9 months (range, 3-12 months). International Prostate Symptom Score decreased a mean of 6.5 points $(P=.005)$, quality of life improved 1.14 points $(P=$ .065), International Index of Erectile Function increased 1.7 points $(P=.063)$, and peak urinary flow increased $3.85 \mathrm{~mL} / \mathrm{sec}(P=$ $.015)$. There was a mean prostate-specific antigen reduction of $2.27 \mathrm{ng} / \mathrm{mL}(P=.072)$ and a mean prostate volume decrease of 26.5 $\mathrm{mL}(P=.0001)$ by ultrasound and $28.9 \mathrm{~mL}(P=.008)$ by magnetic resonance imaging. There was one major complication $\left(\mathrm{a} 1.5-\mathrm{cm}^{2}\right.$ ischemic area of the bladder wall) and four clinical failures $(28.6 \%)$.

CONCLUSIONS: In this small group of patients, PAE was a feasible procedure, with preliminary results and short-term follow-up suggesting good symptom control without sexual dysfunction in suitable candidates, associated with a reduction in prostate volume.

\section{ABBREVIATIONS}

$\mathrm{BPH}=$ benign prostatic hyperplasia, IPSS = international prostate symptom score, PAE = prostatic arterial embolization, PSA = prostate specific antigen, PVA $=$ polyvinyl alcohol, $\mathrm{PVR}=$ postvoid residual volume, $\mathrm{Q}_{\max }=$ peak urinary flow, $\mathrm{QOL}$ $=$ quality of life

Benign prostatic hyperplasia $(\mathrm{BPH})$ has a high prevalence rate in men aged 50-79 years (1) and is ubiquitous with aging (2). $\mathrm{BPH}$ is a condition often associated with lower urinary tract symptoms (3), the most frequent of which are decreased urinary stream, greater frequency, and urgency (4).

Surgery is performed less often now that effective pharmacotherapy is available, but it is an excellent option for

From the Departments of Radiology, (J.M.P., M.D.), Urology (L.C.P.), Anatomy (T.B.), and Biostatistics (A.G.O.), Faculty of Medical Sciences, New University of Lisbon, Rua Luz Soriano, no. 182, 1200-249 Lisbon, Portugal; Department of Angiography (J.M.P., T.B., M.D.), Hospital Saint Louis, Lisbon, Portugal; and Department of Urology (L.C.P., J.R.M.), Curry Cabral Hospital, Lisbon, Portugal. Received May 10, 2010; final revision received September 5, 2010; accepted September 8, 2010. Address correspondence to J.M.P.; E-mail: joao.pisco@chln.min-saude.pt

From the SIR 2010 Annual Meeting.

None of the authors have identified a conflict of interest.

(C) SIR, 2011

J Vasc Interv Radiol 2011; 22:11-19

DOI: 10.1016/j.jvir.2010.09.030 improving symptoms and decreasing progression of disease in patients who develop complications or whose symptoms are inadequately controlled with medical treatment (5).

Prostatectomy by open surgery or by transurethral resection of the prostate is still considered the gold standard of treatment. Alternative options include minimally invasive treatments and prostatic stent placement. Age, symptom scores, grade of obstruction, baseline prostate volume, peak urinary flow $\left(\mathrm{Q}_{\max }\right)$, serum prostate specific antigen (PSA) value, and postvoid residual volume (PVR) are important predictors of clinical progression (6) and, along with individual anesthesiologist risk, are factors that should be taken into consideration when choosing an appropriate treatment (7).

Urinary tract infection, strictures, postoperative pain, incontinence or urinary retention, sexual dysfunction, and blood loss are complications associated with surgical treatments. Minimally invasive treatments were originally conceived as an attempt to offer equivalent efficacy without the burden and risk of operative morbidity. However, they have major disadvantages, such as less effective improvement in 
symptom scores (8), greater risk of continued catheterization and reoperation, and poorer durability of symptomatic benefit (9).

There is the need for innovative technologies to continue to improve outcomes and minimize patient discomfort and morbidity when managing BPH (10). Recently, it was suggested that prostatic arterial embolization (PAE) to treat $\mathrm{BPH}$ might follow uterine artery embolization for uterine leiomyomas (11). Animal studies in pigs and dogs have shown that PAE is safe, with no related sexual dysfunction, and can induce prostatic volume reduction $(12,13)$. The first report of this technique in the management of $\mathrm{BPH}$ in humans was by DeMeritt et al (14), who reported a single case of BPH with obstructive symptoms and blood loss refractory to other treatments that was successfully managed by PAE with $150-250-\mu \mathrm{m}$ polyvinyl alcohol (PVA) particles. More recently there has been a report of two other patients in similar clinical scenarios treated with success with the use of $300-500-\mu \mathrm{m}$ microspheres (15).

We investigated whether PAE might be a feasible procedure as an alternative treatment option to treat $\mathrm{BPH}$ associated symptoms while preserving sexual function. For this purpose, we report preliminary results in 15 patients who underwent PAE with PVA particles as the treatment option in the management of complicated BPH or BPH refractory to medical therapy.

\section{MATERIALS AND METHODS}

\section{Study Population}

A prospective study was undertaken from March 2009 to April 2010 in 15 patients aged 62-82 years (mean, 74.1 y) who presented with symptomatic BPH refractory to medical treatment for at least 6 months (mean International Prostate Symptom Score [IPSS], 21) with a clinical indication for surgery who agreed to undergo PAE. The study was approved by the hospital ethical committee and an informed consent form for PAE as an alternative treatment was signed by all participants. Study criteria included male patients with age greater than 60 years and a diagnosis of BPH with moderate to severe lower urinary tract symptoms (ie, IPSS > 18) refractory to medical treatment for at least 6 months, sexual dysfunction or accepting the risk of developing sexual dysfunction after treatment, and/or $\mathrm{Q}_{\max }$ lower than $12 \mathrm{~mL} / \mathrm{s}$ or acute urinary retention. Malignancy (evaluated by PSA, physical examination, transrectal ultrasound [US], and magnetic resonance [MR] imaging in all patients and by prostatic biopsy in suspicious cases) and advanced atherosclerosis and tortuosity of iliac arteries (based on visual evaluation by the interventional radiologists of pelvic MR angiography performed before PAE in all patients) were exclusion criteria. Patients with minimal to moderate lower urinary tract symptoms were also considered for PAE if $\mathrm{Q}_{\max }$ was lower than $12 \mathrm{~mL} / \mathrm{s}$ if the patients were unsatisfied with the results of medical therapy or had urinary retention.

The patients were not randomized. PAE was not proposed when surgery was indicated for other reasons (eg, secondary renal insufficiency as a result of prostatic obstruction, hematuria, bladder diverticula, or stones).

All patients were informed about the embolization technique used, and the experimental nature was clearly indicated. The patients were allowed to choose freely among PAE, transurethral resection of the prostate/open surgery, or laser surgery. During this time period, 98 patients met the inclusion criteria, of whom 57 opted for transurethral resection/open surgery, 18 for laser surgery, and 23 for PAE. Eight patients were excluded as a result of malignancy in two and advanced atherosclerosis and tortuosity of iliac arteries in six.

All patients were undergoing medical therapy with symptoms that persisted for more than 6 months. Medical therapy was consistent among patients, with each receiving one $\alpha$-1-adrenergic receptor antagonist (alfuzosin $10 \mathrm{mg}$, doxazosin $4 \mathrm{mg}$, or tamsulosin $0.4 \mathrm{mg}$ once daily). One patient had a partial prostatectomy 14 years before and six had bladder catheters at the time as a result of acute urinary retention.

Pelvic MR angiography with a $1.5-\mathrm{T}$ system (Philips, Eindhoven, The Netherlands) was performed before PAE to evaluate the pelvic vessels for tortuosity and atherosclerotic changes of the iliac arteries. All patients were evaluated by clinical observation with measurement of the IPSS and quality of life (QOL)-related symptoms (score from 0 , "delighted"; to 6, "terrible"), sexual function tests (International Index of Erectile Function; score from 0 to 30), uroflowmetry $\left(\mathrm{Q}_{\max }\right.$ and PVR), PSA level, and transrectal US to calculate prostatic volume. Baseline data were obtained before PAE and the response to treatment was measured at 1,3, and 6 months after the procedure. The prostate volume was also measured by MR before and 6 months after PAE (Fig 1).

The prostate diameters were visually measured by transrectal US and MR on the three plane axes: sagittal, cephalocaudal, and transverse. Volumes were assessed with the ellipsoid formula: $\pi / 6 \times$ (transverse diameter $\times$ anteroposterior diameter $\times$ cephalocaudal diameter). One observer performed all transrectal US examinations and another all MR examinations (two experienced radiologists) with the use of these measurement techniques and volume formulas before and after PAE to avoid interobserver variability.

Prostatic biopsy was performed in all cases of suspected prostatic malignancy based on PSA level greater than $4 \mathrm{ng} / \mathrm{mL}$ or suspicious focal lesions detected on transrectal US or MR. All cases positive for malignancy were excluded.

\section{Embolization Technique}

The patients stopped all prostatic medication 1 week before embolization, and after successful PAE, all prostatic medication was abandoned. Patients started an acid-suppressing 

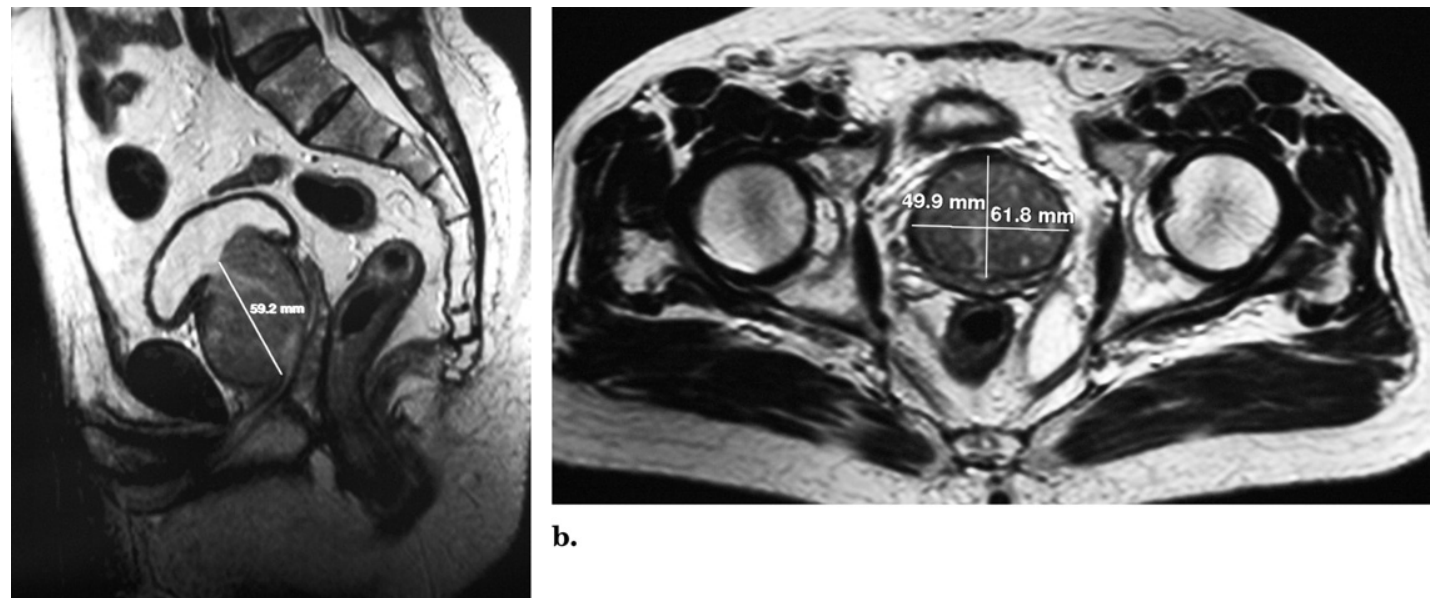

b.

a.
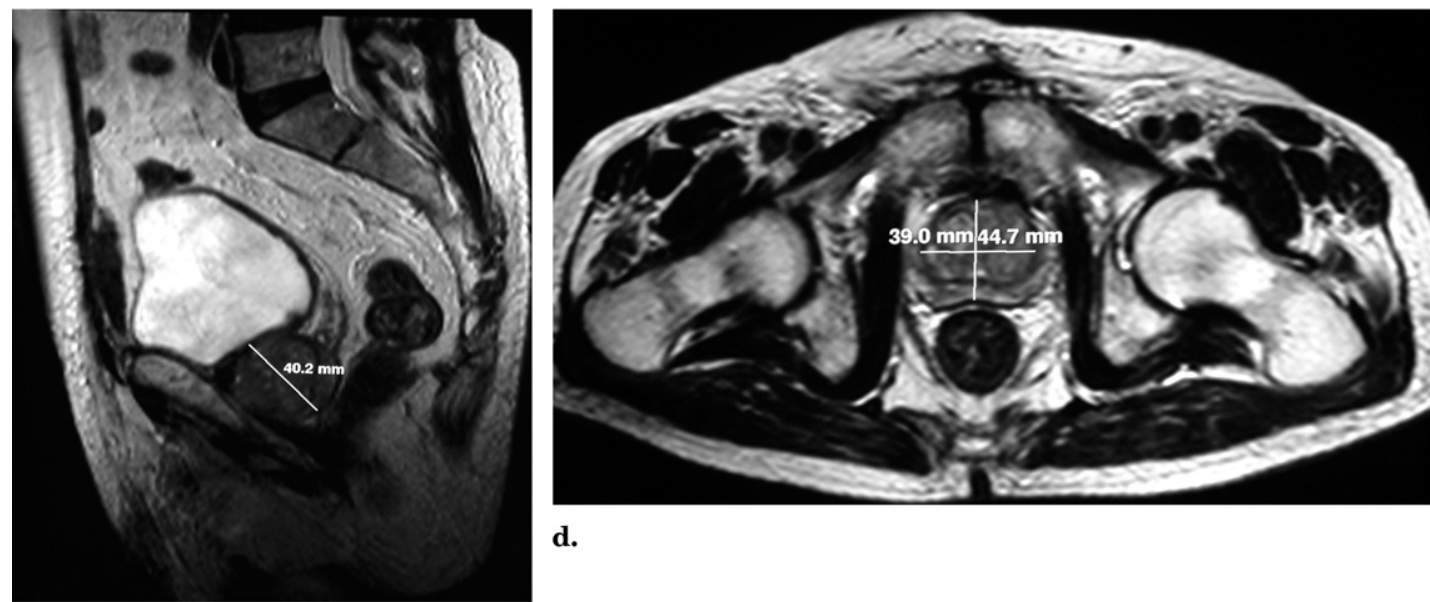

d.

c.

Figure 1. Pelvic MR images in a 78-year-old patient with BPH. (a) Sagittal pelvic MR before PAE shows a prostate cephalocaudal diameter of $59.2 \mathrm{~mm}$ and a prostate volume of $95.5 \mathrm{~mL}$. (b) Axial image before PAE shows prostate sagittal and transverse diameters of $49.9 \times 61.8 \mathrm{~mm}$ and prostate volume of $95.5 \mathrm{~mL}$. (c) Sagittal image 6 months after PAE shows a prostate cephalocaudal diameter of $40.2 \mathrm{~mm}$ and prostate volume of $36.6 \mathrm{~mL}$, a decrease of $61.7 \%$. (d) Axial image 6 months after PAE shows prostate sagittal and transverse diameters of $39.0 \times 44.7 \mathrm{~mm}$ and prostate volume of $36.6 \mathrm{~mL}$, a decrease of $61.7 \%$.

drug (omeprazole $20 \mathrm{mg}$ once daily), and an antiinflammatory agent (naproxen $1,000 \mathrm{mg}$ twice daily) for 2 days before the procedure and continued to receive them for 10 days after PAE. The day of PAE, patients received omeprazole $20 \mathrm{mg}$ and naproxen $1,000 \mathrm{mg}$ in the morning before PAE and naproxen $1,000 \mathrm{mg}$ as postembolization medication 8 hours after PAE. The patients were admitted to the hospital on the day of the procedure. During embolization, analgesic and antiinflammatory drugs were given intravenously (ketorolac $30 \mathrm{mg}$ and metamizole $2 \mathrm{~g}$ intravenously). Embolization was performed under local anesthesia by unilateral approach, usually the right femoral artery. Initially, pelvic angiography was performed to evaluate the iliac and prostatic arteries. Then, a 5-F Cobrashaped catheter (Cordis, Warren, New Jersey) was introduced in right femoral artery to catheterize the left hypogastric artery and reach its anterior division. The inferior vesical artery and finally the prostatic vessels were selectively catheterized with a $3-\mathrm{F}$ coaxial microcatheter
(Progreat; Terumo, Tokyo, Japan). Another angiography study was performed to confirm the position of the catheter in the ostium of the prostatic artery before embolization. For embolization, nonspherical $200-\mu \mathrm{m}$ PVA particles (Cook, Bloomington, Indiana) were used. The endpoint chosen for embolization was slow flow or near-stasis in the prostatic vessels with interruption of the arterial flow and prostatic gland opacification. When embolization of the left prostatic arteries was finished, a Waltman curve was formed on the Cobra catheter and the right prostatic arteries were embolized in the same way (Fig 2). The PAE procedure time was measured starting with femoral puncture access and ending after removal of the catheter after PAE. Fluoroscopy time was also recorded. Pain assessment was performed during PAE and in the 6-8 hours afterward by verbal questioning and written questionnaires with a visual analog scale. Patients were asked to rate their pain severity from 0 (sensation of no pain) to 10 (the worst pain imaginable). 


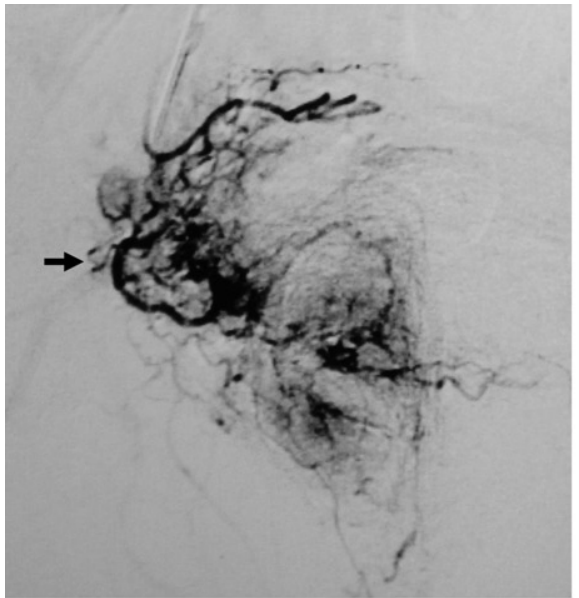

a.

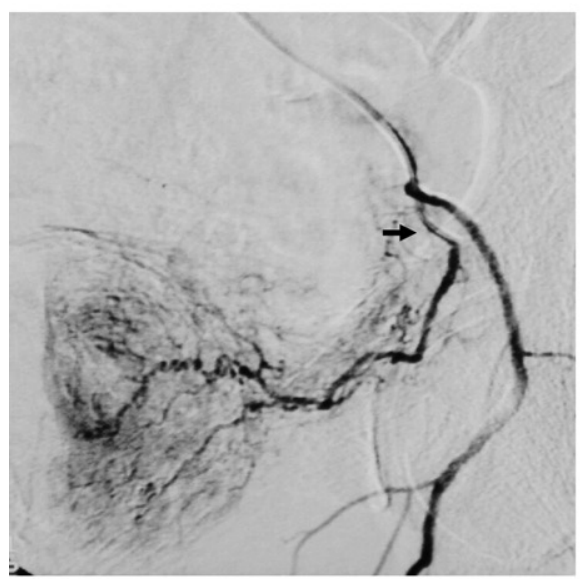

d.

Figure 2. Angiographic findings in a 74-year-old patient with urinary retention with a bladder catheter. Right prostatic arteries before (arrow, a) and after (b) embolization (arrow). (c) After embolization of the right prostatic arteries, in the parenchymal phase of angiography, the prostate is slightly opacified (arrow). The bladder catheter is marked with an arrowhead. Left prostatic arteries before (arrow, d) and after (e) embolization (arrow). Left internal pudendal artery remains patent (arrowhead). (f) After embolization of the left prostatic arteries, in the parenchymal phase of angiography, the prostate is shown with good opacification (arrow). The bladder catheter is marked with an arrowhead.

Symptoms of postembolization syndrome including pain and fever were not considered complications unless pain and/or fever resulted in prolonged hospitalization or hospital readmission. Postprocedural fever was qualified as a complication when a detailed history, physical examination, and laboratory evaluations confirmed a specific etiology. Complications were categorized as complications of angiography (related to puncture site, contrast agents, or radiation injury), pelvic infection, ischemic complications, sexual dysfunction, nonprostatic embolization, adverse drug reactions, pulmonary embolism, and other. Complications were considered minor if they could be addressed by ambulatory medical treatment and major if they resulted in prolonged hospitalization or hospital readmission and/or need for surgery.

\section{Definitions and Outcomes Measures}

The IPSS is a validated questionnaire that is a simple and reliable method to assess the presence, type, and severity of symptoms and the response to treatment (Fig 3) (16). The questionnaire yields a total score ranging from 0 to 35 (1-7 for mild symptoms, 8-19 for moderate, and 20-35 for severe). One additional question (about how men feel about their current urinary symptoms) yields a score for QOL ( 0 , delighted; 6, terrible). The response on the QOL question is a strong predictor for patient management. Objective measurement of uroflowmetry variables such as $\mathrm{Q}_{\max }$ and PVR gives useful information on micturition, and the results can be used to assess severity of obstruction and predict the likelihood of disease progression and response to treatment (17). The normal $Q_{\max }$ in a young healthy adult male subject is approximately $25 \mathrm{~mL} / \mathrm{sec}$, whereas the $\mathrm{Q}_{\max }$ in a patient with BPH reflects a weaker stream and is more stable as a result of urethral compression (Fig 4) (16). When the $\mathrm{Q}_{\max }$ measured by uroflowmetry is lower than 12 $\mathrm{mL} / \mathrm{sec}$, generally it is indicative of BPH.

Sexual dysfunction is frequently associated with BPH and may also occur after treatment. Evaluation of sexual 


\begin{tabular}{|c|c|c|c|c|c|c|c|}
\hline \multicolumn{8}{|c|}{ International Prostate Symptom Score } \\
\hline & $\begin{array}{l}\text { Not at } \\
\text { All }\end{array}$ & $\begin{array}{l}\text { Less } \\
\text { Than } 1 \\
\text { Time in } \\
5\end{array}$ & $\begin{array}{l}\text { Less } \\
\text { Than } \\
\text { Half the } \\
\text { Time }\end{array}$ & $\begin{array}{l}\text { About } \\
\text { Half the } \\
\text { Time }\end{array}$ & $\begin{array}{l}\text { More } \\
\text { Than } \\
\text { Half the } \\
\text { Time }\end{array}$ & $\begin{array}{l}\text { Almost } \\
\text { Always }\end{array}$ & $\begin{array}{l}\text { Your } \\
\text { Score }\end{array}$ \\
\hline $\begin{array}{l}\text { I. INCOMPLETE EMPTYING } \\
\text { Over the past month, how often have you had a } \\
\text { sensation of not emptying your bladder completely } \\
\text { after you finished urinating? }\end{array}$ & 0 & 1 & 2 & 3 & 4 & 5 & \\
\hline $\begin{array}{l}\text { 2. FREQUENCY } \\
\text { Over the past month, how often have you had to } \\
\text { urinate again less than } 2 \text { hours after you finished } \\
\text { urinating? }\end{array}$ & 0 & 1 & 2 & 3 & 4 & 5 & \\
\hline $\begin{array}{l}\text { 3. INTERMITTENCY } \\
\text { Over the past month, how often have you found you } \\
\text { stopped and started several times when you urinated? }\end{array}$ & d? & 1 & 2 & 3 & 4 & 5 & \\
\hline $\begin{array}{l}\text { 4. URGENCY } \\
\text { Over the past month, how often have you found it } \\
\text { difficult to postpone urination? }\end{array}$ & 0 & 1 & 2 & 3 & 4 & 5 & \\
\hline $\begin{array}{l}\text { 5. WEAK STREAM } \\
\text { Over the past month, how often have you had a weak } \\
\text { urinary stream? }\end{array}$ & k & 1 & 2 & 3 & 4 & 5 & \\
\hline $\begin{array}{l}\text { 6. STRAINING } \\
\text { Over the past month, how often have you had to } \\
\text { push or strain to begin urination? }\end{array}$ & 0 & 1 & 2 & 3 & 4 & 5 & \\
\hline \multirow[t]{4}{*}{$\begin{array}{l}\text { 7. NOCTURIA } \\
\text { Over the past month, how many times did you most } \\
\text { typically get up to urinate from the time you went to } \\
\text { bed at night until the time you got up in the } \\
\text { morning? }\end{array}$} & t & 1 & 2 & 3 & 4 & 5 & \\
\hline & \multicolumn{7}{|c|}{ Which of the above do you regard as most troublesome? $(1-7)$} \\
\hline & \multicolumn{7}{|c|}{ TOTAL PROSTATE SYMPTOM SCORE_ } \\
\hline & Delighted & Pleased & $\begin{array}{c}\text { Mostly } \\
\text { Satisfied }\end{array}$ & $\begin{array}{l}\text { Mixed-- } \\
\text { Satisfied } \\
\text { and Dis- } \\
\text { satisfied }\end{array}$ & $\begin{array}{c}\text { Mostly } \\
\text { Dis- } \\
\text { satisfied }\end{array}$ & Unhappy & Terrible \\
\hline $\begin{array}{l}\text { QUALITY OF LIFE DUE TO URINARY } \\
\text { SYMPTOMS } \\
\text { If you were to spend the rest of your life with } \\
\text { your urinary condition just the way it is now, } \\
\text { how would you feel about that? (pick one) }\end{array}$ & 0 & 1 & 2 & 3 & 4 & 5 & 6 \\
\hline
\end{tabular}

Figure 3. IPSS form. Adapted from Burnett AL, Wein AJ. Benign prostatic hyperplasia in primary care: what you need to know. J Urol 2006; 175(Suppl):S19-S24, with permission from Elsevier.

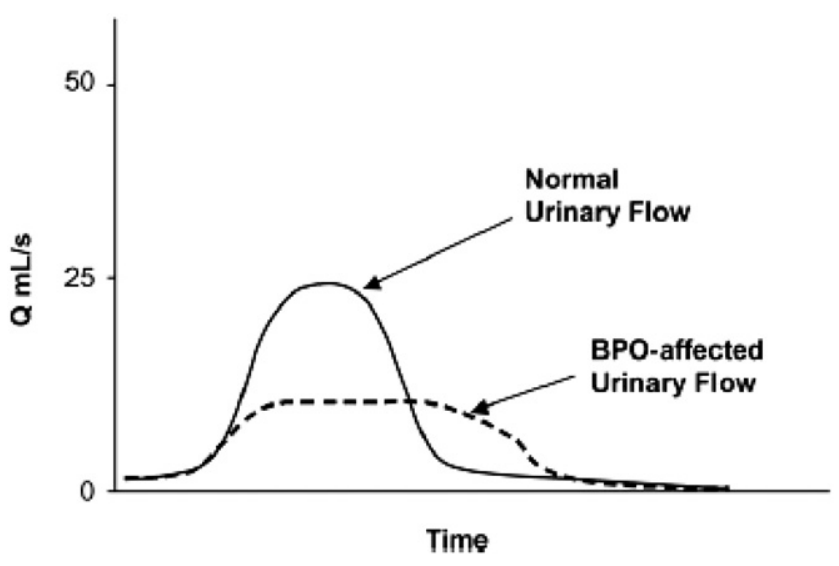

Figure 4. BPH effects on urinary flow. $Q$ is urinary flow rate in $\mathrm{mL} / \mathrm{sec}$. $B P O$ is benign prostatic obstruction. Adapted from Burnett $A L$, Wein $A J$. Benign prostatic hyperplasia in primary care: what you need to know. J Urol 2006; 175(Suppl):S19-S24, with permission from Elsevier. function can be assessed with the International Index of Erectile Function, a widely used, multidimensional selfreporting instrument that has been recommended as a primary endpoint for clinical trials and for diagnostic evaluation of erectile dysfunction severity (18).

Technical success was considered when selective prostatic arterial catheterization and embolization was achieved at least on one pelvic side.

Cases of persisting severe symptoms (ie, IPSS $\geq 20$ ) and/or $\mathrm{Q}_{\max }$ of $7 \mathrm{~mL} / \mathrm{sec}$ or lower after PAE were considered clinical failures. Possible ischemic, infectious, or puncture site complications were evaluated by clinical and physical examination with pain assessment the day after PAE and weekly in the following months. Further imaging or laboratory studies were used when a complication was suspected. Clinical success was based on intent to treat and defined as improvement of symptoms (IPSS reduction with 


\begin{tabular}{|c|c|c|c|c|c|}
\hline \multirow[b]{2}{*}{ Variable } & \multirow{2}{*}{$\begin{array}{l}\text { No. of } \\
\text { Pts. }\end{array}$} & \multicolumn{2}{|c|}{ Measurement* } & \multirow[b]{2}{*}{ Mean Differencet } & \multirow[b]{2}{*}{$P$ Value } \\
\hline & & Baseline & Last Follow-up & & \\
\hline IPSS & 8 & $21.0 \pm 8.38$ & $14.5 \pm 8.00$ & $-6.5 \pm 1.58$ & .005 \\
\hline QOL & 7 & $3.86 \pm 1.07$ & $2.71 \pm 1.38$ & $-1.14 \pm 0.51$ & .065 \\
\hline IIEF & 14 & $16.2 \pm 9.42$ & $17.9 \pm 8.77$ & $1.71 \pm 0.84$ & .063 \\
\hline PSA (ng/mL) & 14 & $8.76 \pm 6.69$ & $6.49 \pm 6.73$ & $-2.27 \pm 1.16$ & .072 \\
\hline $\mathrm{Q}_{\max }(\mathrm{mL} / \mathrm{sec})$ & 8 & $7.06 \pm 2.63$ & $10.91 \pm 5.34$ & $3.85 \pm 1.21$ & .015 \\
\hline \multicolumn{6}{|c|}{ Prostate volume $(\mathrm{mL})$} \\
\hline On US & 14 & $97.4 \pm 27.0$ & $70.9 \pm 24.3$ & $-26.5 \pm 4.62$ & .0001 \\
\hline On MR & 9 & $104.9 \pm 36.3$ & $76.0 \pm 27.9$ & $-28.9 \pm 8.28$ & .008 \\
\hline PVR (mL) & 8 & $130.8 \pm 30.8$ & $51.3 \pm 21.8$ & $-79.5 \pm 12.4$ & .0004 \\
\hline
\end{tabular}

Note. - IIEF = International Index of Erectile Function.

* Values presented as means \pm SD.

$\dagger$ Values presented as means \pm SEM.

score $<20$ ) and/or improvement of $\mathrm{Q}_{\max }$ to greater than 7 $\mathrm{mL} / \mathrm{sec}$ after PAE.

\section{Statistical Analysis}

For comparisons of baseline and outcome variables, the paired $t$ test and Shapiro-Wilk test were used. Stata software (release 10; Stata, College Station, Texas) was used for all statistical analyses. Statistically significant differences were assumed at a $P$ value lower than .05 .

\section{RESULTS}

Nine patients underwent prostatic biopsy in view of high PSA levels ( $>4 \mathrm{ng} / \mathrm{mL}$ ) to exclude malignancy. All biopsy findings were negative for neoplasia.

PAE was technically successful in 14 of the 15 patients (93.3\%). In one patient (6.7\%), the procedure was impossible as a result of tortuosity and atherosclerotic changes of the iliac arteries; surgery was required in this case. We performed PAE bilaterally in 13 patients (technical success rate for bilateral PAE, 86.7\%) and unilaterally in one patient (patient 11) as a result of tortuosity and atherosclerotic changes of the iliac arteries. In these two patients with tortuosity and atherosclerotic changes of the iliac arteries considered for PAE, pelvic MR angiography showed common and external iliac artery patency without significant atherosclerotic changes, without defining the extent of atherosclerosis in the internal iliac arteries inside the pelvis.

The PAE procedure lasted between 25 and 135 minutes (mean, $85 \mathrm{~min}$ ) and fluoroscopy time ranged between 15 and 45 minutes (mean, $35 \mathrm{~min}$ ). Mean follow-up was 7.9 months (range, 3-12 months). Only one vial of 200- $\mu$ m PVA particles was used in each patient.

Six patients had urinary retention with vesical catheters. Only one patient (patient 10) felt pain during embolization; no other patient experienced pain during or after the procedure. Twelve patients were discharged from the hos- pital 6-8 hours after the procedure (ie, outpatients) and the remaining three patients were discharged 18 hours after (the next morning; ie, inpatients). Vesical catheters were removed 5 days after the procedure in four patients and 10 days after PAE in the remaining three.

Baseline data of the 14 treated patients are shown in Table 1. Before PAE, the mean IPSS score was $21 \pm 8.38$, the mean QOL score was $3.86 \pm 1.07$, the mean sexual function score was $16.2 \pm 9.42$, the mean PSA was 8.76 $\mathrm{ng} / \mathrm{mL} \pm 6.69$, the mean $\mathrm{Q}_{\max }$ was $7.06 \mathrm{~mL} / \mathrm{sec} \pm 2.63$, and the mean PVR was $130.8 \mathrm{~mL} \pm 30.8$. The mean baseline prostate volumes were $97.4 \mathrm{~mL} \pm 27.0$ calculated by US and $104.9 \mathrm{~mL} \pm 36.3$ calculated by MR.

One month after PAE, without any prostatic medication, there was a mean reduction of the IPSS of 6.7 points, of the QOL score of 1 point (indicating an improvement), and of the mean sexual function score of 0.9 points. The mean $\mathrm{Q}_{\max }$ increased 1.6 points, the mean PSA decreased $25.8 \%$, and there was a mean prostate volume reduction of $22 \%$. The stability of the results was confirmed on subsequent examinations. Follow-up at 1 and 3 months was possible in all patients; follow-up at 6 months was possible in nine patients (Table 2). One patient with colon carcinoma and lung metastases died at 3 months after PAE. The remaining four patients are currently doing well and await follow-up examination at 6 and 12 months.

At the last follow-up - at 3 months (in five patients) and 6 months (in nine patients) - there was a mean decrease in the IPSS of 6.5 points $(P=.005)$, a mean improvement in QOL (ie, score reduction) of 1.14 points $(P=.065)$, and a mean increase in the sexual function score of 1.71 points $(P=.063)$. There was a mean PSA reduction of 2.27 $\mathrm{ng} / \mathrm{mL}(P=.072)$, a mean $\mathrm{Q}_{\max }$ increase of $3.85 \mathrm{~mL} / \mathrm{sec}$ $(P=.015)$, and a mean prostate volume decrease of 26.5 $\mathrm{mL}$ on US $(P=.0001)$ and $28.9 \mathrm{~mL}$ on $\mathrm{MR}(P=.008)$. There was a PVR reduction of $79.5 \mathrm{~mL}(P=.0004)$.

Minor complications were seen in two patients with urinary tract infections after embolization treated with an- 


\begin{tabular}{|c|c|c|c|c|c|c|c|c|c|c|c|c|c|c|c|c|c|}
\hline \multirow{2}{*}{$\begin{array}{l}\text { Pt. No/ } \\
\text { Age (y) }\end{array}$} & \multicolumn{2}{|c|}{ IPSS } & \multicolumn{2}{|c|}{ QoL } & \multicolumn{2}{|c|}{ IIEF } & \multicolumn{2}{|c|}{ PSA (ng/mL) } & \multicolumn{2}{|c|}{$\mathrm{Q}_{\max }(\mathrm{mL} / \mathrm{s})$} & \multicolumn{2}{|c|}{$\begin{array}{c}\text { US Prostate } \\
\text { Volume } \\
\text { (mL) }\end{array}$} & \multicolumn{2}{|c|}{$\begin{array}{c}\text { MR Prostate } \\
\text { Volume } \\
\text { (mL) } \\
\end{array}$} & \multicolumn{2}{|c|}{ PVR (mL) } & \multirow{2}{*}{$\begin{array}{l}\text { Follow- } \\
\text { up (mo) }\end{array}$} \\
\hline & Before & After & Before & After & Before & After & Before & After & Before & After & Before & After & Before & After & Before & After & \\
\hline $1 / 76$ & TCD & 3 & TCD & 1 & 17 & 20 & 15 & 3.48 & TCD & 15.2 & 91 & 32 & 95 & 37 & TCD & 23 & 12 \\
\hline $2 / 74$ & 16 & 14 & 3 & 3 & 6 & 11 & 3.9 & 4.2 & 5.2 & 8.2 & 122 & 93 & 132 & 94 & 160 & 60 & 11 \\
\hline $3 / 78$ & 26 & 17 & 5 & 4 & 28 & 28 & 24 & 15.0 & 7.6 & 6.4 & 143 & 120 & 185 & 124 & 97 & 40 & 10 \\
\hline $4 / 78$ & 33 & 26 & 5 & 4 & 2 & 4 & 3.12 & 2.34 & 5.7 & 6.9 & 59 & 45 & 60 & & 185 & 54 & $3^{*}$ \\
\hline $5 / 76$ & TCD & 4 & TCD & 1 & 15 & 15 & 8.6 & 6.4 & $\mathrm{TCD}$ & 24.2 & 118 & 86 & 107 & 52 & TCD & 15 & 9 \\
\hline $6 / 74$ & 22 & 7 & 4 & 1 & 13 & 22 & 2.29 & 2.69 & 10 & 16.7 & 61 & 41 & 58 & 42 & 103 & 41 & 9 \\
\hline $7 / 72$ & TCD & 11 & TCD & 3 & 15 & 15 & 3.17 & 1.75 & TCD & 9.5 & 96 & 74 & 98 & 82 & TCD & 14 & 9 \\
\hline $8 / 77$ & 8 & 6 & 2 & 1 & 15 & 14 & 5.1 & 2.54 & 11.2 & 20.5 & 120 & 83 & 98 & 80 & 121 & 37 & 9 \\
\hline 9/71 & TCD & 5 & TCD & 2 & 24 & 24 & 9.3 & 8.51 & TCD & 8.5 & 76 & 67 & 74 & 80 & TCD & 52 & 9 \\
\hline $10 / 70$ & 29 & 26 & 4 & 4 & 27 & 27 & 3.21 & 4.38 & 3.1 & 5.0 & 96 & 94 & 97 & 93 & 106 & 56 & 9 \\
\hline $11 / 73$ & 13 & 8 & 2 & 2 & 12 & 19 & 11.01 & 9 & 6.1 & 12.5 & 64 & 59 & 76 & - & 129 & 97 & 5 \\
\hline $12 / 62$ & TCD & 19 & TCD & 3 & 30 & 30 & 20 & 26 & TCD & 4 & 121 & 85 & 112 & - & TCD & 31 & 5 \\
\hline $13 / 82$ & 21 & 12 & 4 & 1 & 23 & 22 & 6.9 & 1.13 & 7.6 & 11.1 & 77 & 52 & 78 & - & 145 & 25 & 5 \\
\hline $14 / 74$ & TCD & 5 & TCD & 1 & 0 & 0 & 7.04 & 3.41 & TCD & 12.3 & 119 & 61 & 119 & - & TCD & 78 & 5 \\
\hline
\end{tabular}

Note. - IIEF $=$ International Index of Erectile Function; TCD $=$ transurethral catheter drainage.

* Patient died.

tibiotics and one patient with acute urinary retention after PAE (patient 10). For relief, a bladder catheter was placed at the time. A major complications was seen in one case $(7.1 \%)$ of a small area $\left(1.5 \mathrm{~cm}^{2}\right)$ of bladder wall ischemia in the right side of the base without involvement of the ureteral or urethral orifices (the same patient with intraprocedural pain; patient 10). The area of ischemia at the bladder base was removed by surgery without further complications.

There were four cases $(28.6 \%)$ that were considered clinical failures (patients 3, 4, 10, and 12). Two had persisting severe symptoms after PAE (IPSS persisted $>20$ in patients 4 and 10) and all had a $\mathrm{Q}_{\max }$ no greater than 7 $\mathrm{mL} / \mathrm{s}$.

Patient 10 required further surgery to treat the area of ischemia at the bladder base and had persisting prostatic symptoms. However, all remaining patients were doing well at the time of last follow-up, stopped all prostatic medication, and reported no sexual dysfunction. There was no need for prostatic surgery after PAE in any other case.

\section{DISCUSSION}

Experimental animal studies in pigs and dogs have shown that PAE can induce prostatic volume reduction and that it is safe, with no associated sexual dysfunction $(12,13)$. Prostatic embolization to control severe hemorrhage has also been successfully performed in human subjects in different case series $(19,20)$. Also, case reports in human subjects have shown that PAE is safe and can induce prostate volume reduction and relief of obstruction-related voiding symptoms $(14,15)$. In the present study, we report the preliminary results of prostatic embolization for BPH-related symptoms in a small series of human patients.

In the study by DeMeritt et al (14), the IPSS decreased from 24 to 13 after 1 year, the prostatic volume was reduced by $40 \%$ at 5 and 12 months, and the PSA level decreased from $40 \mathrm{ng} / \mathrm{mL}$ to $4 \mathrm{ng} / \mathrm{mL}$ (ie, $90 \%$ reduction). There was no sexual dysfunction after the treatment (14). In this study, unilateral embolization was performed with a good outcome.

Prostate size may not be related to obstruction severity, so unilateral embolization may achieve enough organ ischemia to allow symptom improvement, even with lower volume reduction. It may be possible that, unlike uterine artery embolization, PAE might be successful only with unilateral embolization - the criteria chosen in the present study for technical success.

In the study by Carnevale et al (15), one of the patients underwent embolization on one side, with $27.8 \%$ prostate volume reduction, and the other patient underwent embolization on both sides, with a $47.8 \%$ volume decrease at 6 months. However, in this study (15), clinical evaluation of IPSS, QOL, sexual function, PSA, $\mathrm{Q}_{\max }$, and PVR was not performed.

In the present study, despite the withdrawal of all prostatic medications after PAE, there was a significant improvement of the IPSS (mean improvement of 6.5 points; range, $2-16$ points). QOL improved in all but three patients whose QOL remained stable (patients 2, 10, and 11). The sexual function improved in five patients and remained stable in nine (variations in score of 1 point are considered 
clinically insignificant). The improvement of erectile function might be explained by the discontinuation of all prostatic medication after PAE, although these results were not statistically significant. There was a tendency for PSA reduction in almost all cases. There were four patients with insignificant increases in PSA (patients 2, 6, 10, and 12, the latter related to prostatic biopsy). There was a significant improvement in $\mathrm{Q}_{\max }$ (mean improvement of $3.85 \mathrm{~mL} / \mathrm{sec}$; range, $9.3-1.2 \mathrm{~mL} / \mathrm{sec}$ ). There was a significant prostate volume reduction in all patients (mean reduction, 26.5-28.9 $\mathrm{mL}$; range, $7.8 \%-64.8 \%$, the former reduction in a patient with unilateral PAE). PVR decreased significantly in all patients.

Despite the general improvement in most parameters evaluated, there were four clinical failures $(28.6 \%)$ with persisting severe symptomatology after PAE (ie, IPSS $\geq 20$ points) or $\mathrm{Q}_{\max }$ remaining lower than $7 \mathrm{~mL} / \mathrm{sec}$ after PAE. Most of these patients had severe symptoms before PAE despite prostatic medical therapy and had partial relief after PAE without the need for further prostatic medication. Despite the persisting symptoms, three patients are currently doing well without the need for prostatic medication or surgery. One patient (patient 10) required surgery for prostatic symptomatic relief and removal of a small area of ischemia at the bladder base.

Minor IPSS improvements (ie, $<3$ points) after PAE were observed in two patients (patients 2 and 8 ) and were not considered clinical failures because both patients remained with acceptable moderate-to-low IPSS score after PAE despite receiving no prostatic medication. Also, both patients showed an improvement in $\mathrm{Q}_{\max }$ to greater than $7 \mathrm{~mL} / \mathrm{sec}$.

The lowest reduction of prostate volume and PVR after PAE occurred in patient 10 (the patient with bladder necrosis) and patient 11 (the patient who underwent unilateral embolization). Because of the intraprocedural pain caused by bladder necrosis in patient 10 , an incomplete embolization was performed.

It is interesting to note that patient 11 , who underwent unilateral embolization, had only a $7.8 \%$ prostatic volume reduction. Even so, his IPSS score improved five points (from 13 to 8) and his $\mathrm{Q}_{\max }$ almost doubled (increase of 6.4 $\mathrm{mL} / \mathrm{sec}$ from 6.1 to $12.5 \mathrm{~mL} / \mathrm{sec}$ ). Also, we found a poor correlation between prostatic volume reduction and clinical outcome. These results may imply that prostatic volume reduction might not be the only mechanism that allows symptom improvement after PAE, as it is also noted that there is a weak correlation between prostate size and lower urinary tract symptoms. Further studies are warranted to confirm this hypothesis.

Pelvic MR angiography was performed in all patients to exclude patients with extensive arterial occlusive disease. Age range and male sex are important risk factors associated with BPH and atherosclerotic changes that may pose a contraindication to the procedure.

In contrast to uterine artery embolization, we noted minimal postembolization symptoms in our study patients. The antiinflammatory drugs used before, during, and after
PAE may be enough to prevent possible embolizationrelated symptoms. Only one patient (patient 10) felt intraprocedural pain, and this patient later developed a small area of bladder wall ischemia. The fact that a more extensive embolization of the bladder vessels was performed in this patient because the prostatic arteries had a proximal origin near the branches of the inferior vesical artery might explain the complication. After surgical removal of the $1.5-\mathrm{cm}^{2}$ zone of ischemia of the bladder wall, the patient's symptoms improved. There were no cases of nausea or vomiting. All patients who underwent PAE (except patient 10) were doing well at the time of last follow-up, with stable or with some improvement in sexual function, without any prostate-specific medication or need for prostate surgery. The preservation of sexual function and the minimally invasive and nonsurgical nature of this procedure are great advantages.

The present study has some limitations. We were not able to measure the IPSS, QOL, and $\mathrm{Q}_{\max }$ in the six patients who underwent transurethral catheter drainage before PAE. Therefore, the mean IPSS, QOL, and $\mathrm{Q}_{\max }$ before PAE were based on eight patients, and only changes from baseline could be evaluated in these patients. Also, there were no pressure-flow urodynamics performed, there was no placebo or comparator arm, there was a short follow-up period, and the study was not randomized. The endpoint follow-up period in the group was not the same for all patients and it was not possible to assess the time to maximal effects, size reduction, and possible time to recurrence.

This study did not intend to compare PAE with placebo, medical therapies, or surgery, so it is not possible to imply if these clinical results after PAE could be comparable to placebo or medical therapy mainly because these were all patients who were receiving prostatic medication and stopped all medication after the procedure, with good outcomes. There is some evidence that other factors besides prostatic volume reduction may account for clinical outcomes after PAE. Further studies are warranted to confirm this hypothesis and to compare PAE with placebo and medical and surgical therapies.

Although the results are preliminary with a small number of patients and a short follow-up period, they are very promising. More studies are needed with greater numbers of patients, different sizes of PVA particles, and longer follow-up to asses if the procedure can be an effective and a safe alternative in the management of BPH.

We conclude that PAE is a feasible procedure, with preliminary results and short-term follow-up suggesting good symptom control without sexual dysfunction in suitable candidates, associated with a reduction in prostate volume.

\section{REFERENCES}

1. Garraway WM, Collins GN, Lee RJ. High prevalence of benign prostatic hypertrophy in the community. Lancet 1991; 338:469-471.

2. Kassabian VS. Sexual function in patients treated for benign prostatic hyperplasia. Lancet 2003; 361:60-62. 
3. Rosen RC, Giuliano F, Carson CC. Sexual dysfunction and lower urinary tract symptoms (LUTS) associated with benign prostatic hyperplasia (BPH). Eur Urol 2005; 47:824-837.

4. Eckhardt MD, van Venrooij GE, van Melick HH, Boon TA. Prevalence and bothersomeness of lower urinary tract symptoms in benign prostatic hyperplasia and their impact on well-being. J Urol 2001; 166:563-568.

5. Patel AK, Chapple CR. Benign prostatic hyperplasia: treatment in primary care. Br Med J 2006; 333:535-539.

6. Crawford ED, Wilson SS, McConnell JD, et al; MTOPS Research Group. Baseline factors as predictors of clinical progression of benign prostatic hyperplasia in men treated with placebo. J Urol 2006; 175 1422-1426.

7. Miano R, De Nunzio C, Asimakopoulos AD, Germani S, Tubaro A Treatment options for benign prostatic hyperplasia in older men. Med Sci Monit 2008; 14:RA94-RA102.

8. van Melick HH, van Venrooij GE, Eckhardt MD, Boon TA. A randomized controlled trial comparing transurethral resection of the prostate, contact laser prostatectomy and electrovaporization in men with benign prostatic hyperplasia: analysis of subjective changes, morbidity and mortality. J Urol 2003; 169:1411-1416.

9. Lourenco T, Pickard R, Vale L, et al; Benign Prostatic Enlargement Team. Minimally invasive treatments for benign prostatic enlargement: systematic review of randomised controlled trials. Br Med J 2008; 337: a1662.

10. Baazeem A, Elhilali MM. Surgical management of benign prostatic hyperplasia: current evidence. Nat Clin Pract Urol 2008; 5:540-549.

11. Mauro MA. Can hyperplastic prostate follow uterine fibroids and be managed with transcatheter arterial embolization? Radiology 2008; 246:657-658.
12. Sun F, Sánchez FM, Crisóstomo V, et al. Benign prostatic hyperplasia: transcatheter arterial embolization as potential treatmentpreliminary study in pigs. Radiology 2008; 246:783-789.

13. Jeon GS, Won JH, Lee BM, et al. The effect of transarterial prostate embolization in hormone-induced benign prostatic hyperplasia in dogs: a pilot study. J Vasc Interv Radiol 2009; 20:384-390.

14. DeMeritt JS, Elmasri FF, Esposito MP, Rosenberg GS. Relief of benign prostatic hyperplasia-related bladder outlet obstruction after transarteria polyvinyl alcohol prostate embolization. J Vasc Interv Radiol 2000; 11: 767-770.

15. Carnevale FC, Antunes AA, da Motta Leal Filho JM, et al. Prostatic artery embolization as a primary treatment for benign prostatic hyperplasia: preliminary results in two patients. Cardiovasc Intervent Radiol 2010; 33:355-361.

16. Burnett $A L$, Wein AJ. Benign prostatic hyperplasia in primary care: what you need to know. J Urol 2006; 175(Suppl):S19-S24.

17. Wilt TJ, N'Dow J. Benign prostatic hyperplasia. Part 1-diagnosis. $\mathrm{Br}$ Med J 2008; 336:146-149.

18. Rosen RC, Cappelleri JC, Gendrano N III. The International Index of Erectile Function (IIEF): a state-of-the-science review. Int J Impot Res 2002; 14:226-244

19. Rastinehad AR, Caplin DM, Ost MC, et al. Selective arterial prostatic embolization (SAPE) for refractory hematuria of prostatic origin. Urology 2008; 71:181-184.

20. Nabi G, Sheikh N, Greene D, Marsh R. Therapeutic transcatheter arterial embolization in the management of intractable haemorrhage from pelvic urological malignancies: preliminary experience and longterm follow-up. BJU Int 2003; 92:245-247. 